\title{
Erratum: A genetic and computational approach to structurally classify neuronal subtypes
}

\author{
Uygar Sümbül, Sen Song, Kyle McCulloch, Michael Becker, Bin Lin, Joshua R. Sanes, Richard H. Masland \\ $\&$ H. Sebastian Seung
}

Nature Communications 5:3512 doi: 10.1038/ncomms4512 (2014); Published 24 Mar 2014; Updated 18 Sep 2014

There were errors associated with the Supplementary Data in the version of this Article originally published, which were introduced while the HTML was being prepared. The titles of Supplementary Data 8, 9, 10,11, 12 and 13 were incorrectly linked to Supplementary Data 7, 8, 9, 10, 11 and 12, respectively, and the file for Supplementary Data 13 was omitted. These errors have now been corrected in the HTML version of the Article; the PDF was correct from the time of publication. 